\title{
LOW SPEED OPERATION OF DSP BASED PWM CONTROL OF 4 PHASE 8/6 SWITCHED RELUCTANCE MOTOR DRIVE
}

\author{
P.SRINIVAS \\ Dept. of Electrical Engg., University College of Engineering, \\ Osmania University, Hyderabad, India, e-mail: srinivasp.eedou@gmail.com
}

\begin{abstract}
This paper presents the speed control of 4 phase 8/6 Switched Reluctance Motor drive with PWM controller. The motor is fed from an Asymmetrical bridge converter, because of its fault tolerant capability and all the phases are independently excited. The Hall sensors provided in the motor provide signals corresponding to the position of the rotor. The speed is controlled by varying the duty ratio of the PWM controller. The pulses to the IGBT switches are generated using a Digital Signal Processor. The SRM drive with PWM controller is simulated in MATLAB/SIMULINK and also experimentally implemented at no load \& partial load. The waveforms of the PWM signals and phase currents are captured by means of Digital storage oscilloscope and compared with the simulation results.
\end{abstract}

Keywords: PWM Controller, Switched Reluctance Motor, Digital Signal Processor

\section{INTRODUCTION}

The Switched Reluctance Motor (SRM) is a good competitor to conventional AC/DC drives in variable speed applications because of its advantages like high speed, high robustness, high reliability, low cost, and high rotor temperature handling capability [1], [2].The phase winding is to be excited during the positive increasing region of the phase inductance to get the motoring action. This is done through an Asymmetrical converter,asit has advantages that both the hard chopping and soft chopping are possible. The control strategies of SRM are mainly the Hysteresis Current Control, PWM Control and the Single Pulse Voltage Control. Hysteresis Current Control and PWM Control are used for low and medium speed operations. The Single Pulse Voltage Control controls the speed and torque by regulating the turn-on and turn-off angles. This is suitable for high speed operation, but not to low speed operation because of high current peaks [3],[4],[5]. The speed control of Asymmetrical converter fed 4 phase SRM using DSP is investigated experimentally in [6].

This paper presents the speed control of 4 phase $8 / 6$ SRM using DSP TMS320F2407A. Simulation and experimental results are presented to verify the PWM Controller.

\section{PRINCIPLE OF PWM}

Two significantly different methods namely Hysteresis current control and PWM control are used below the base speed operation of the motor. The basic difference between the two is that Hysteresis type controllers aim to control the current during the conduction period whereas PWM type controllers control the average phase voltage during conduction period [7],[8]. In this control, the average phase voltage during the conduction period is controlled by varying the duty ratio of the top switch. At the end of the conduction interval both switches are opened, in which case the phase voltage is equal to $\mathrm{V}_{\mathrm{dc}}$ for the time interval in which the phase current is greater than zero. This type of control has a constant PWM switching frequency, which can be advantageous in terms of reduction in acoustic noise.

\section{MATHEMATICAL ANALYSIS}

$V=\frac{D T_{p w m} V_{d c}+(1-D) T_{p w m}}{T_{p w m}}$

Where $V_{d c}$ is the dc link voltage, $\mathrm{D}$ is the PWM duty ratio and $\mathrm{T}_{\mathrm{pwm}}$ is the $\mathrm{PWM}$ period

$V_{\text {ave }}=\frac{\sum_{i=1}^{n} D_{i} T_{p w m i} V_{d c}}{\sum_{i=1}^{n} T_{p w m i}}$

Where $\mathrm{n}$ is the PWM period number of each conduction time, $\mathrm{D}_{\mathrm{i}}$ and $\mathrm{T}_{\text {pwmi }}$ present the duty ratio and period of each PWM cycle respectively. For SRM average terminal voltage can be expressed as

$V_{a v e}=i R+L \frac{d i}{d t}+i \omega \frac{d L}{d \theta}$

Where $\mathrm{i}$ is the phase current, $\mathrm{L}$ is the phase inductance and $\omega$ is the speed.

$T=\sum_{i=1}^{n} \frac{\partial W}{\partial \theta}$

Where $\mathrm{n}$ is the number of phases and $\mathrm{W}$ is the coenergy which could be calculated from

$W=\frac{1}{2} i^{2} L$

$T=\frac{1}{2} i^{2} \frac{\partial L}{\partial \theta}$

$\frac{\sum_{i=1}^{n} D_{i} T_{p w m i} V_{d c}}{\sum_{i=1}^{n} T_{p w m i}} i=i^{2} R+\frac{d\left(\frac{1}{2} L i^{2}\right)}{d t}+T \omega$ 
It is clear that by changing the duty ratio, output torque and speed can be controlled

\section{BLOCK DIAGRAM}

The whole setup consists of following important units viz TMS320F2407A DSP Controller, IGBT Intelligent Power Module (IPM), SRM, Signal Conditioner and Mechanical loading arrangement. The interconnections of these units are shown in the block schematic diagram of Fig 1. The IPM consists of a single phase bridge rectifier with capacitors at the output. This rectifier provides the rectified DC voltage to the IGBT based Asymmetrical bridge converter. The IPM is rated for $25 \mathrm{~A}, 1200 \mathrm{~V}$. Hall Effect transducers are used to sense the dc link current, dc link voltage and the output currents of the converter. The heart of the closed loop control scheme is the DSP controller. The inputs to the DSP are provided through 26 pin connector. The various analog inputs to the DSP are dc link current $I_{D C}$, dc link voltage $V_{D C}$, the four phase currents of the IGBT converter $\mathrm{I}_{1}, \mathrm{I}_{2}, \mathrm{I}_{3}$ and $\mathrm{I}_{4}$ and isolated fault signal. These are given through signal conditioner block. The digital inputs are Hall sensor signals.

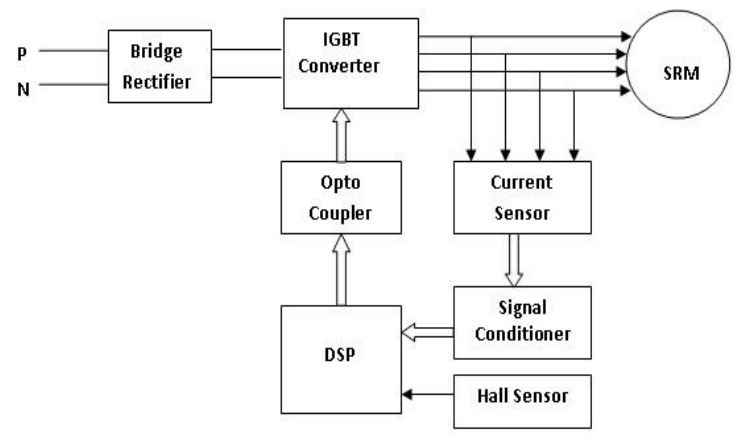

Fig. 1 Block Schematic Diagram of Control Scheme

\section{SOFTWARE IMPLEMENTATION}

An assembly language program was developed to operate the SRM in closed loop mode. The program generates PWM signals which are applied to the IGBTs of the converter. The motor is protected against over/under voltage, over current and rise in temperature by software. The reference speed is given as an input through an external potentiometer which is interfaced to the inbuilt analog to digital converter (ADC) of the DSP. The program at start features the following tasks: (a) Initialization of all registers of DSP and resetting watchdog (b) Configuring the MUX control register, ADC, timer control registers in the Event Manager (c) Initialization of all the variables (d) Enabling of timer interrupts and watchdog (e) Hall sensor encoder is set at 00 (f) Low duty cycle of PWMs for soft start action of motor. After the soft start action, the duty cycle of PWM signals are varied by the program to achieve the required speed. In closed loop control mode, the ADC of the DSP is configured to capture reference and feedback signals. After evaluating the error and amplifying it, the duty ratio of the PWM is varied to implement PWM control. The flow chart for closed loop operation is shown in Fig. 2
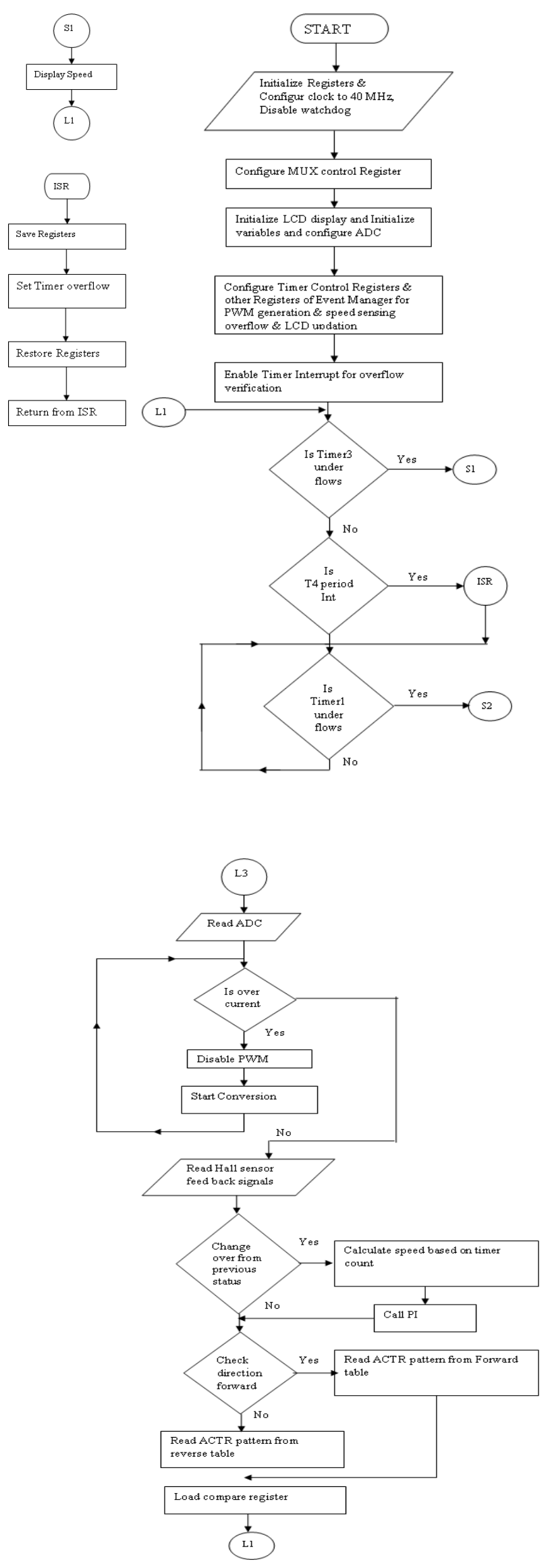


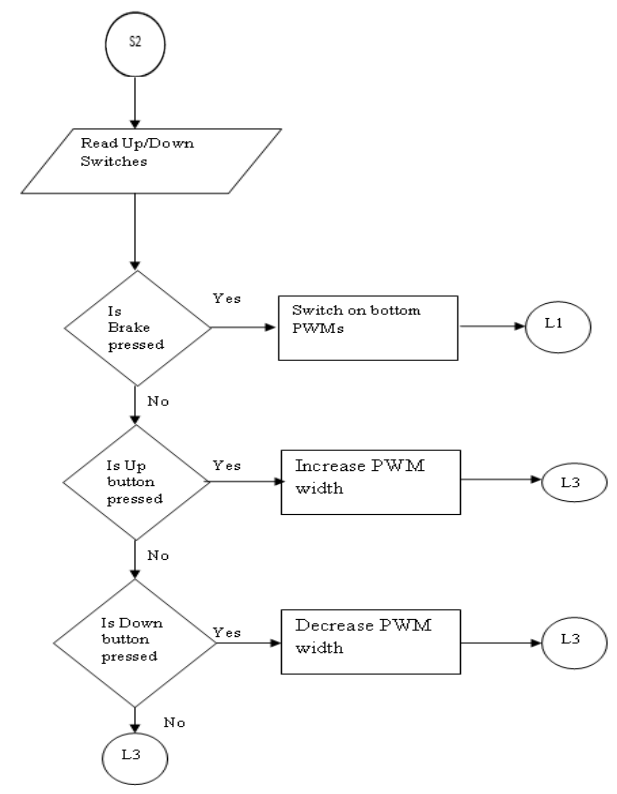

Fig. 2 Flow chart of closed loop operation of the drive

\section{SIMULATION}

The SRM drive is simulated [9] with the PWM Controller at $20 \mathrm{kHz}$ under no load and at partial $(0.75$ $\mathrm{Nm}$ ) load conditions. The rated speed of the motor is 6000 rpm. The specifications of SR Motor is given in Appendix. The speed is maintained constant at $1400 \mathrm{rpm}$. The phase current waveforms of four phases under no load condition at low speed of $1400 \mathrm{rpm}$ are shown in Fig. 3 (a). Fig. 3 (b) shows the PWM signal and current in one phase. The phase current waveforms of four phases under load condition at $1400 \mathrm{rpm}$ are shown in Fig. 4 (a). Fig. 4 (b) shows of the PWM signal and current in one phase.

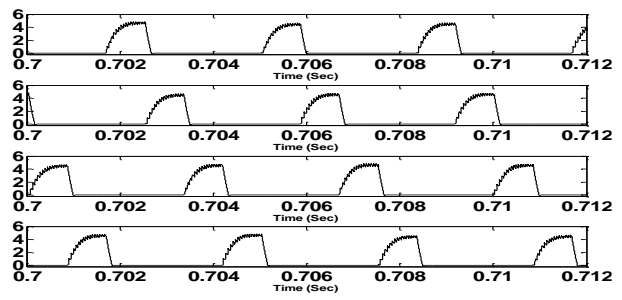

(a)

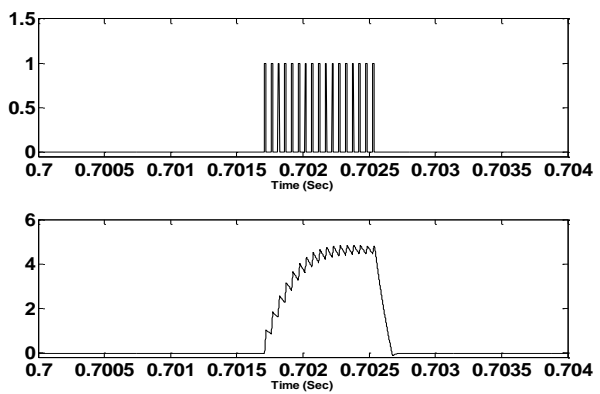

(b)

Fig. 3 Simulation waveforms of the drive at No load, 1400rpm (a) Phase current waveforms of four phases (b)PWM signal and current in one phase

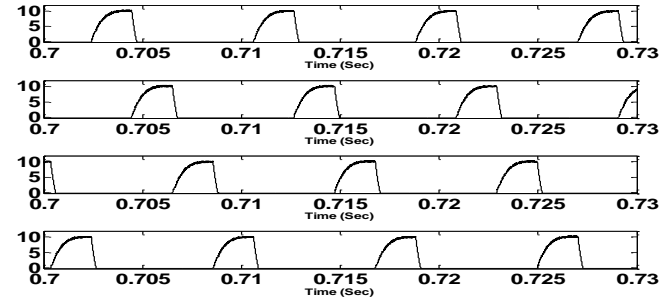

(a)

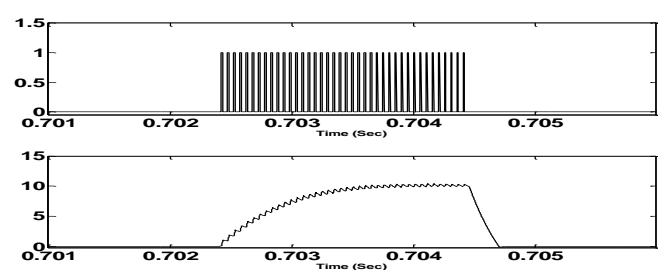

(b)

Fig. 4 Simulation waveforms of the drive under load, 1400 RPM (a) Phase current waveforms of four phases (b) PWM signal and current in one phase

\section{EXPERIMENTAL RESULTS}

The PWM control of SRM drive was operated from no-load and partial-load at $1400 \mathrm{rpm}$ in closed -loop mode. The PWM frequency is set at $20 \mathrm{kHz}$. The phase current waveforms of four phases under no load condition at $1400 \mathrm{rpm}$ are shown in Fig. 5 (a). Fig. 5 (b) shows the PWM signal and current in one phase. The phase current waveforms of four phases under load condition at 1400 rpm are shown in Fig. 6 (a). Fig. 6 (b) shows the PWM signal and current in one phase

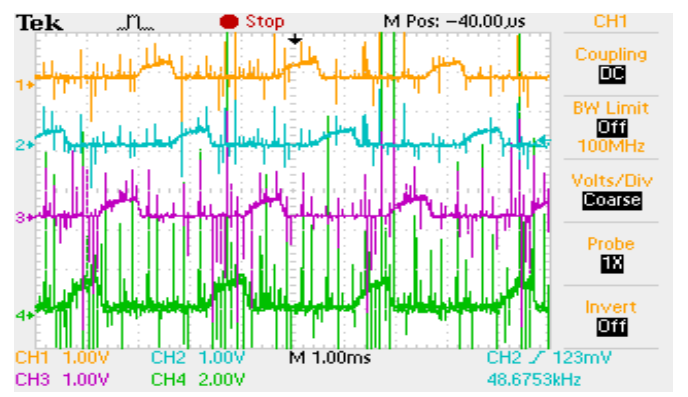

(a)

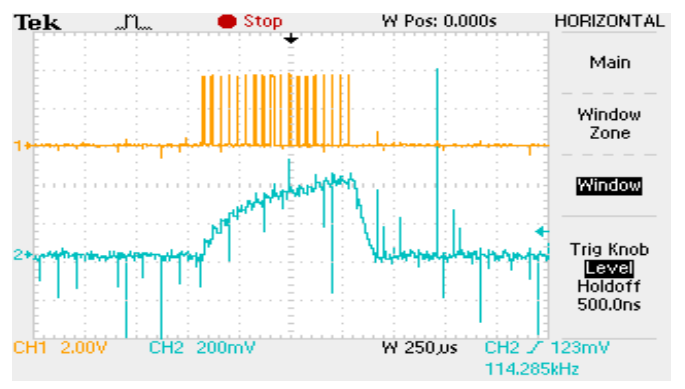

(b)

Fig. 5 Experimental waveforms of the drive at No load, 1400 RPM (a) Phase current waveforms of four phases (b) PWM signal and current in one phase 


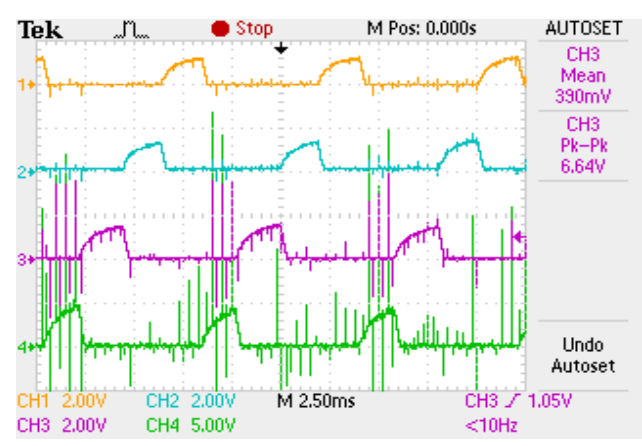

(a)

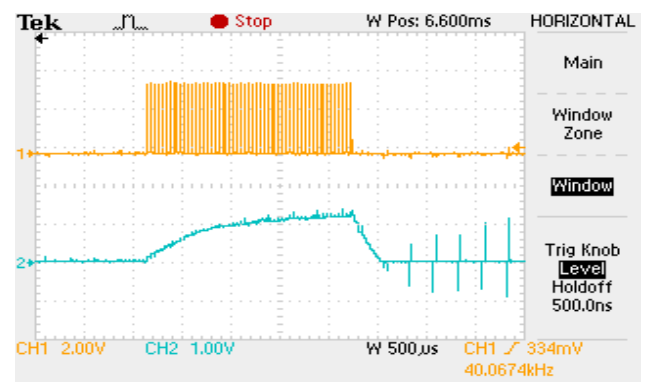

(b)

Fig. 6 Experimental waveforms of the drive under load, 1400 RPM (a) Phase current waveforms of four phases (b)PWM signal and current in one phase

\section{CONCLUSIONS}

The low speed operation of 4 phase $8 / 6 \mathrm{SRM}$ is analyzed using PWM controlstrategy. The performance of the PWM Controller based SRM driveis tested by simulationand through experimentation. The simulation is conducted in MATLAB/SIMULINK. PWM pulses are generated by DSP processor. The phase currents and PWM signals are captured by Digital Storage Oscilloscope. It is observed that the simulation results are in correlation with experimental results. It is concluded that the PWM control operation at low speed is satisfactory with minimum current ripples under no load and partial load.

\section{REFERENCES}

[1] KRISHNAN, R.: Switched Reluctance Motor Drives: modeling, simulation, analysis, design, and applications: CRC press, 2001

[2] MILLER, T. J. E.: Switched Reluctance Motors and their Control: Magna Physics \& Oxford,1993.

[3] SOARES, F. - COSTA BRANCO, P. J.: Simulation of a $6 / 4$ Switched Reluctance Motor based on Matlab/Simulink environment.IEEE Transactions on Aerospace and Electronic Systems, 2001.
[4] RAJARATHNAM, A. V. - RAHMAN, K. M. EHSANI, M.: Improvement of hysteresis control in switched reluctance motor drives, IEEE International Conference on Electric Machines and Drives, pp. 537-539, 1999 .

[5] SRINIVAS, P. - PRASAD, P. V. N.: Voltage Control and Hysteresis Current Control of a $8 / 6$ Switched Reluctance Motor. Proceedings of IEEE International Conference on Electrical Machines \& Systems, pp. 1557-1562,2007.

[6] CHANCHAROENSOOK, P. - RAHMAN,M. F.: A DSP based Speed control of a four phase 8/6 switched Reluctance Motor Drive, Proceedings of Austrialian Universities Power Engineering Conference, 2004.

[7] BAIMING SHAO - EMADI, A.: A digital PWM control for Switched Reluctance Motor drives. Proceedings of IEEE International Conference on Vehicle Power and Propulsion, pp.1-6,2010.

[8] RIK DE DONCKER - DUCOW, J. PULLE ANDREVELTAM: Advanced Electrical Drives: Analysis, Modeling and Control, Springer, 2011.

[9] HUY, H. LE. - BRUNELLE, P.: A versatile nonlinear switched reluctancemotor model in Simulink using realistic and analytical magnetizationcharacteristics.Proceedings of $31^{\text {st }}$ IEEE Annual Conference of the Industrial Electronics Society, 2005.

Received September 19, 2014, accepted January 16, 2015

\section{BIOGRAPHIES}

P.Srinivas graduated in Electrical \& Electronics Engg. from Kakatiya University, Warangal in 1998 and received M.Tech. in Electrical Machines \& Industrial Drives from NIT,Warangal in 2000. Presently he is serving as Assistant Professor in the Department of Electrical Engineering, Osmania University. He received his Ph.D in Electrical Engineering from Osmania University in 2013. His areas of interest are Special Electrical Machines. He has got twelve International papers and presented technical papers in South Korea, USA and Singapore.

\section{Appendix \\ SRM Specifications}

Rated Voltage: $\quad 48 \mathrm{~V}$

Power: $1 \mathrm{HP}$

Current: $\quad 10 \mathrm{~A}$

Speed: $\quad 6000 \mathrm{rpm}$ 